\title{
Methane emissions among individual dairy cows during milking quantified by eructation peaks or ratio with carbon dioxide
}

\author{
M. J. Bell, N. Saunders, R. H. Wilcox, E. M. Homer, J. R. Goodman, J. Craigon, and P. C. Garnsworthy ${ }^{1}$ \\ The University of Nottingham, School of Biosciences, Sutton Bonington Campus, Loughborough LE12 5RD, UK
}

\begin{abstract}
The aims of this study were to compare methods for examining measurements of $\mathrm{CH}_{4}$ and $\mathrm{CO}_{2}$ emissions of dairy cows during milking and to assess repeatability and variation of $\mathrm{CH}_{4}$ emissions among individual dairy cows. Measurements of $\mathrm{CH}_{4}$ and $\mathrm{CO}_{2}$ emissions from 36 cows were collected in 3 consecutive feeding periods. In the first period, cows were fed a commercial partial mixed ration (PMR) containing $69 \%$ forage. In the second and third periods, the same 36 cows were fed a high-forage PMR ration containing $75 \%$ forage, with either a high grass silage or high maize silage content. Emissions of $\mathrm{CH}_{4}$ during each milking were examined using 2 methods. First, peaks in $\mathrm{CH}_{4}$ concentration due to eructations during milking were quantified. Second, ratios of $\mathrm{CH}_{4}$ and $\mathrm{CO}_{2}$ average concentrations during milking were calculated. A linear mixed model was used to assess differences between PMR. Variation in $\mathrm{CH}_{4}$ emissions was observed among cows after adjusting for effects of lactation number, week of lactation, diet, individual cow, and feeding period, with coefficients of variation estimated from variance components ranging from 11 to $14 \%$ across diets and methods of quantifying emissions. No significant difference was detected between the $3 \mathrm{PMR}$ in $\mathrm{CH}_{4}$ emissions estimated by either method. Emissions of $\mathrm{CH}_{4}$ calculated from eructation peaks or as $\mathrm{CH}_{4}$ to $\mathrm{CO}_{2}$ ratio were positively associated with forage dry matter intake. Ranking of cows according to $\mathrm{CH}_{4}$ emissions on different diets was correlated for both methods, although rank correlations and repeatability were greater for $\mathrm{CH}_{4}$ concentration from eructation peaks than for $\mathrm{CH}_{4}$-to- $\mathrm{CO}_{2}$ ratio. We conclude that quantifying enteric $\mathrm{CH}_{4}$ emissions either using eructation peaks in concentration or as $\mathrm{CH}_{4}$-to$\mathrm{CO}_{2}$ ratio can provide highly repeatable phenotypes for ranking cows on $\mathrm{CH}_{4}$ output.
\end{abstract}

Key words: dairy cow, methane, carbon dioxide, phenotype, repeatability

Received December 31, 2013.

Accepted July 3, 2014.

${ }^{1}$ Corresponding author: Phil.Garnsworthy@nottingham.ac.uk

\section{INTRODUCTION}

Enteric methane $\left(\mathrm{CH}_{4}\right)$ emissions from ruminants have gained research interest due to the association between greenhouse gas concentrations in the atmosphere and global climate change. A large proportion of the variation in enteric $\mathrm{CH}_{4}$ emissions from animals can be explained by diet composition and feed intake (Bell and Eckard, 2012). In addition to the variation in $\mathrm{CH}_{4}$ explained by diet, considerable variation exists among individual dairy cows (de Haas et al., 2011; Garnsworthy et al., 2012a; Huhtanen et al., 2013), suggesting a scope for selective breeding. Compared with diet manipulation, outcomes of selective breeding are permanent and cumulative. A repeatable and accurate phenotype is required, however, to allow selection of animals for reduced emissions.

Use of respiration chambers is impractical for largescale estimation of $\mathrm{CH}_{4}$ emissions by individual cows on commercial dairy farms. Quantifying enteric $\mathrm{CH}_{4}$ emissions during milking by using low-cost and mobile technologies has been demonstrated to provide repeatable phenotypic estimates of $\mathrm{CH}_{4}$ emissions under commercial conditions (Garnsworthy et al., 2012a,b; Lassen et al., 2012). In the study of Garnsworthy et al. (2012a), estimates of $\mathrm{CH}_{4}$ made during milking were correlated with total daily $\mathrm{CH}_{4}$ emissions by the same cows when housed subsequently in respiration chambers.

The studies of Garnsworthy et al. (2012a) and Lassen et al. (2012) used similar technologies for measuring $\mathrm{CH}_{4}$; both sampled gas from the feed bin of automatic (robotic) milking stations while cows were being milked, and measured $\mathrm{CH}_{4}$ concentrations with portable gas analyzers. Subsequent handling and analysis of data, however, differed between studies; Garnsworthy et al. (2012a) analyzed $\mathrm{CH}_{4}$ only released by eructation, whereas Lassen et al. (2012) calculated ratios of average $\mathrm{CH}_{4}$ to average $\mathrm{CO}_{2}$ concentrations of cows throughout milking, as proposed by Madsen et al. (2010). The equivalence of these 2 approaches is unknown, but is fundamentally important for comparison of findings from these and subsequent studies.

The objective of the current study was to assess repeatability and variation in $\mathrm{CH}_{4}$ and $\mathrm{CO}_{2}$ emissions 
from eructation peaks, average concentrations during milking, and their ratio, by dairy cows fed on diets differing in forage composition.

\section{MATERIALS AND METHODS}

Animal work was conducted under the authority of the United Kingdom Animal (Scientific Procedures) Act 1986, and approval was obtained from the University of Nottingham animal ethics committee (Sutton Bonington, UK) before commencement of the study.

\section{Data}

Concentrations of $\mathrm{CH}_{4}$ and $\mathrm{CO}_{2}$ from Holstein-Friesian dairy cows were measured during milking at Nottingham University Dairy Centre (Sutton Bonington, UK). Cows were group housed in a freestall barn and milked individually at an automatic (robotic) milking station (AMS). Gas concentrations in air sampled from the feed bin of the AMS were measured continuously by infrared analyzers (Guardian Plus; Edinburgh Instruments Ltd., Livingston, UK) throughout the sampling period of $35 \mathrm{~d}$. For a full description of the technique, see Garnsworthy et al. (2012a). The technique is briefly described below.

The $\mathrm{CH}_{4}$ and $\mathrm{CO}_{2}$ concentrations were logged at 1-s intervals on data loggers (Simex SRD-99; Simex Sp. z o.o., Gdańsk, Poland) and visualized using logging software (Loggy Soft; Simex Sp. z o.o.). Analyzers were calibrated using standard mixtures of gases in nitrogen (0.0 and 1.0\% $\mathrm{CH}_{4}$, and 5\% $\mathrm{CO}_{2}$; Thames Restek UK Ltd., Saunderton, UK).

Concentrations of $\mathrm{CH}_{4}$ and $\mathrm{CO}_{2}$ measured in parts per million ( $\mathrm{vol} / \mathrm{vol}$ ) were converted to milligrams per liter by assuming the density of $\mathrm{CH}_{4}$ to be $655.7 \mathrm{mg} / \mathrm{L}$ and $\mathrm{CO}_{2}$ to be $1798.9 \mathrm{mg} / \mathrm{L}$ at $25^{\circ} \mathrm{C}, 1$ atmosphere $(101.3 \mathrm{kPa})$ pressure, with the analyzer sampling air at $1 \mathrm{~L} / \mathrm{min}$. Concentrations of $\mathrm{CH}_{4}$ and $\mathrm{CO}_{2}$ emitted during each milking were calculated from (1) area under the curve of eructation peaks [integral of concentrations minus concentration at the start of each peak; $(\mathrm{mg} / \mathrm{L}) \cdot \mathrm{min}]$, multiplied by frequency of eructation peaks (peaks per minute) or (2) average concentration during the milking period minus the minimum (baseline or background) concentration at the start of the milking (Figure 1). Method 1 used a custom-designed program to identify and quantify eructation peaks of $\mathrm{CH}_{4}$ concentration during milking (eructation $\mathrm{CH}_{4}$ ) from raw logger data (Garnsworthy et al., 2012a). In method 1, milkings with less than 3 eructation peaks for $\mathrm{CH}_{4}$ concentration were excluded from the analysis. Peaks of $\mathrm{CO}_{2}$ concentration were not calculated using this method due to lack of distinct peaks originating from eructation (Figure 1). Method 2 used the average of all recorded $\mathrm{CH}_{4}$ (average $\mathrm{CH}_{4}$ ) and $\mathrm{CO}_{2}$ (average $\mathrm{CO}_{2}$ ) concentrations $(\mathrm{mg} / \mathrm{L})$ during each milking to derive the ratio of $\mathrm{CH}_{4}$ to $\mathrm{CO}_{2}$ concentrations (expressed as $\mathrm{g} / \mathrm{kg}$ ).

Emissions were measured during 3 consecutive feeding periods, in which cows were fed partial mixed rations (PMR; Table 1) ad libitum plus concentrates during milking (AMS concentrates). In the first period, 36 cows were fed for $7 \mathrm{~d}$ a commercial PMR containing $69 \%$ forage (Table 1). In the second and third periods, the same 36 cows were fed, in a 14-d crossover design, PMR containing $75 \%$ forage with high proportions of either grass silage or maize silage (Table 1). Feeding periods followed immediately with no adjustment period between diets. The daily AMS concentrate allowance fed during milking was $1.5 \mathrm{~kg}$ plus $0.16 \mathrm{~kg}$ per liter of milk yield above $23 \mathrm{~L} / \mathrm{d}$. The AMS concentrates were dispensed into the feed bin at $360 \mathrm{~g} / \mathrm{min}$ in 6 portions per minute throughout the milking period, which helped to keep the cow's head within suitable proximity of the gas sampling tube. The AMS concentrate dispensers were calibrated monthly by weighing quantities dispensed. The AMS concentrate manufacturer's declared specification per kilogram as fed was as follows: ME: 12.2 MJ, CP: 16\%, NDF: 24\%, starch: $21 \%$, and fat: $6.2 \%$. Milk yield, BW, and AMS concentrate intake were recorded automatically at each milking. Dry matter intake of PMR was recorded automatically by electronic feeders. Total daily DMI of concentrates was calculated from AMS concentrate intake plus intake of concentrates in the PMR.

For comparison with other studies, the method of Madsen et al. (2010) was used to estimate daily heat produced by each cow in megajoules per day $(5.6 \times \mathrm{kg}$ of $\mathrm{BW}^{0.75}+22 \times \mathrm{kg}$ of milk yield per day +0.000016 $\times$ days pregnant ${ }^{3} \times 0.0864$ ), which was then converted to estimated $\mathrm{CO}_{2}$ emissions in grams per day.

\section{Statistical Analysis}

Data were analyzed using a linear mixed model in GenStat software (version 15.1; VSN International Ltd., Hemel Hempstead, UK; Lawes Agricultural Trust, 2012). Equation 1 was used to assess the effect of diet on average DMI, milk yield (both $\mathrm{kg} / \mathrm{d}$ ), average number of milkings per day, average duration of milking (s), BW (kg), eructation $\mathrm{CH}_{4}$, average $\mathrm{CH}_{4}$, average $\mathrm{CO}_{2}$, and $\mathrm{CH}_{4}$-to- $\mathrm{CO}_{2}$ ratio per individual cow:

$$
y_{i j k}=\mu+L_{i}+W_{j}+D_{i}+C_{j}+C_{j} P_{k}+E_{j k},
$$


a)
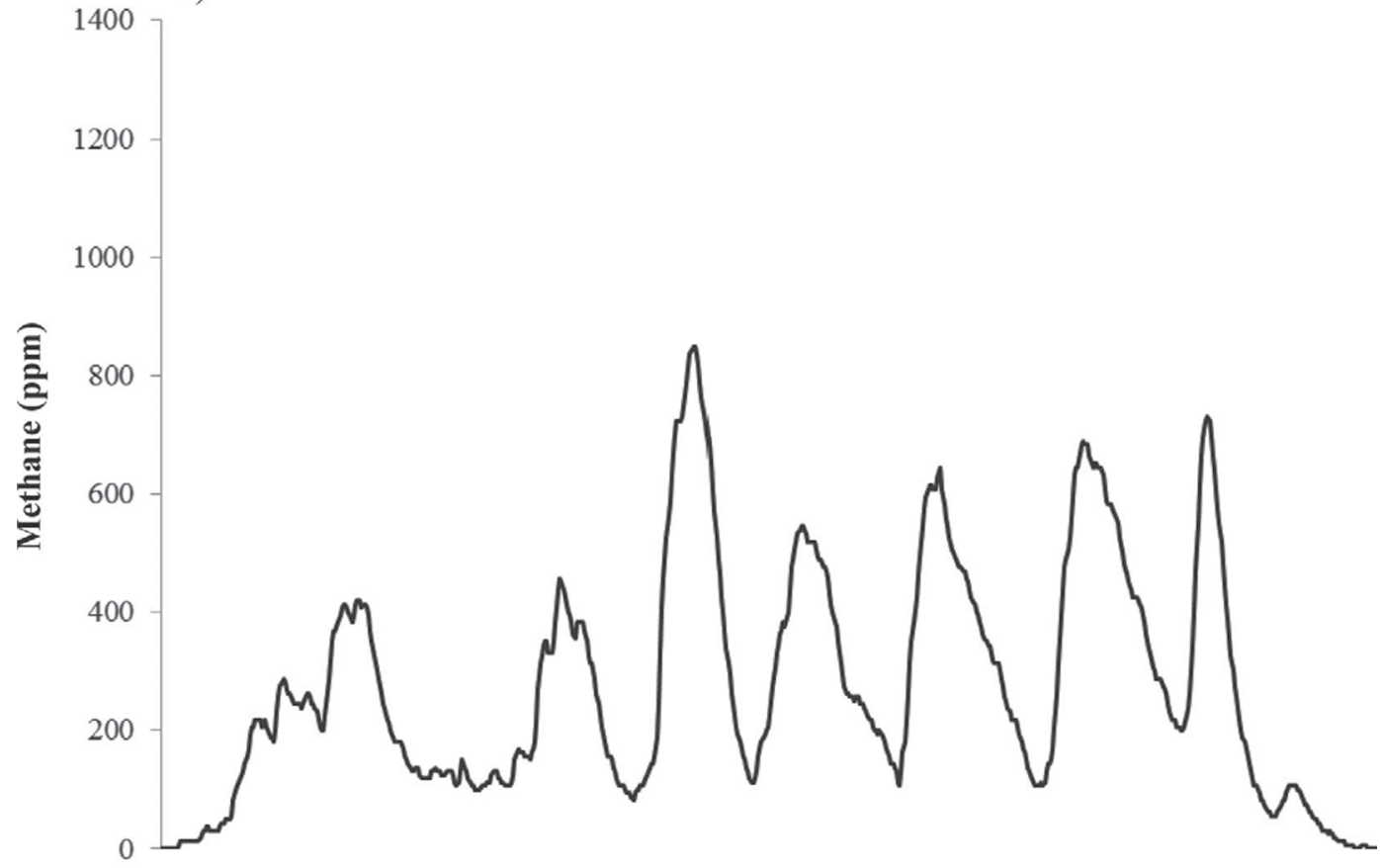

b)

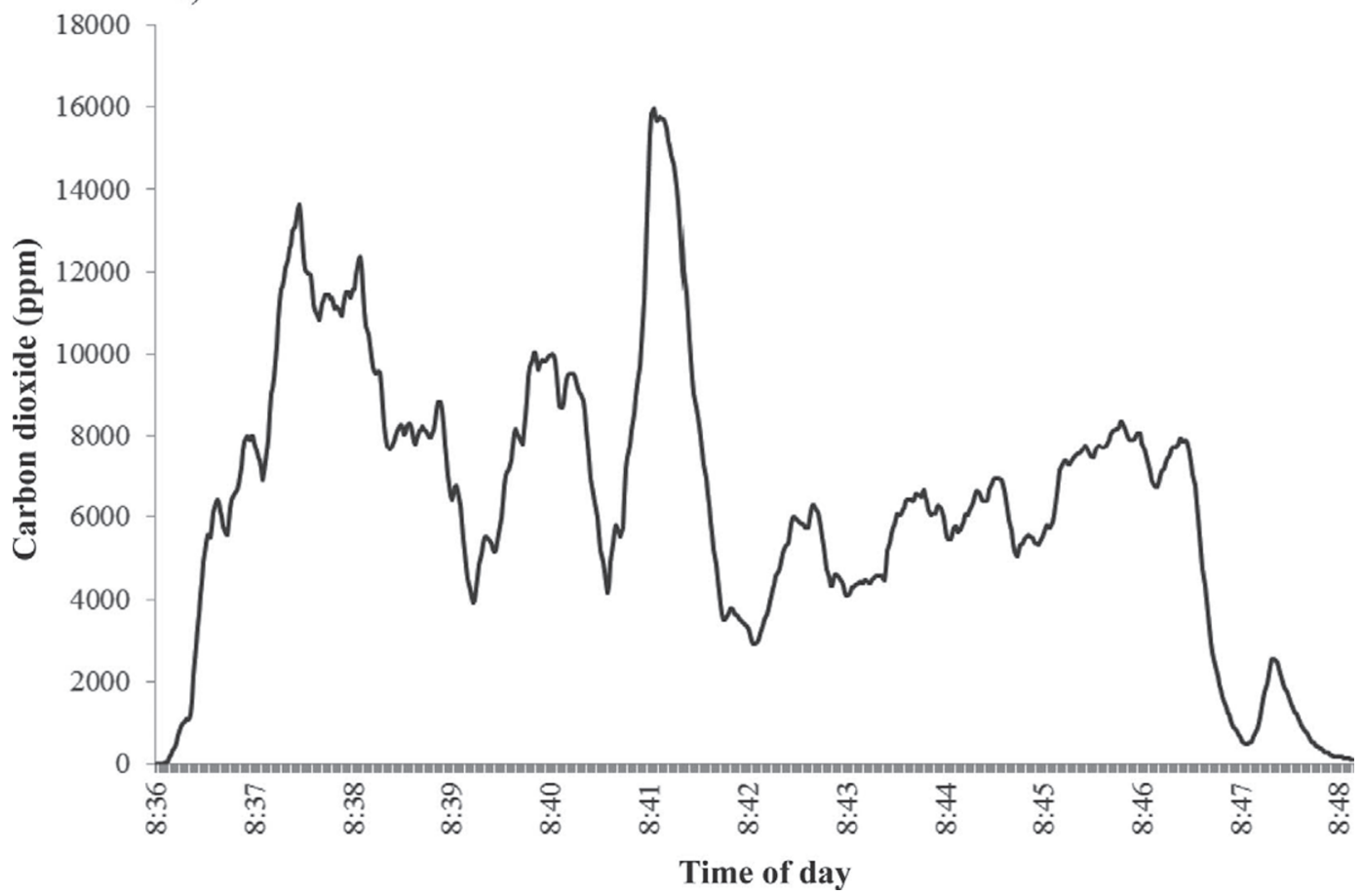

Figure 1. Concentration in parts per million of (a) $\mathrm{CH}_{4}$ and (b) $\mathrm{CO}_{2}$ during a single milking visualized by the data logging software (Loggy Soft; Simex Sp. z o.o., Gdańsk, Poland).

where $y_{i j k}$ is the dependent variable, $\mu=$ overall mean, $=$ random effect of sampling period within cow, and $E_{j k}$ $L_{i}=$ fixed effect of lactation number $(1,2$, or $3+), W_{j}==$ random error term $(\mathrm{df}=53)$.

fixed effect of week of lactation $(1,2,3, \ldots), D_{i}=$ fixed The residual coefficient of variation was calculated effect of diet, $C_{j}=$ random effect of individual cow, $P_{k}$ from variance components as root mean square error 


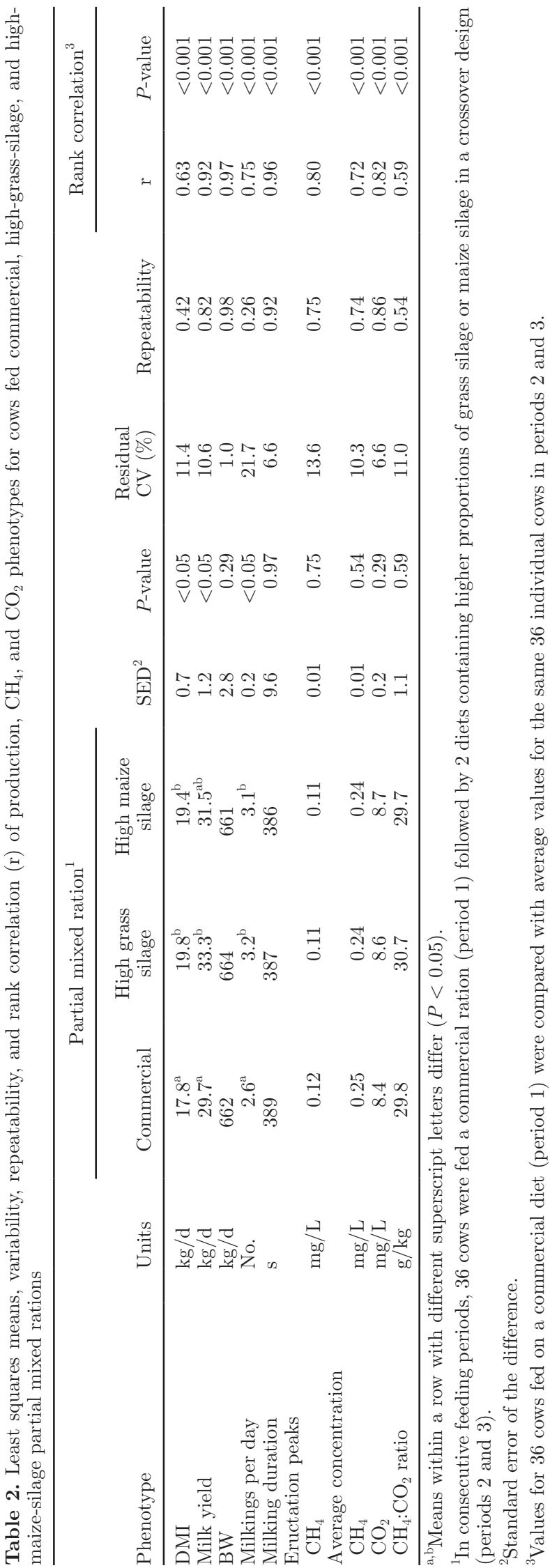

\section{Variation Among Cows and Repeatability of Phenotypes}

Residual coefficient of variation was slightly greater for eructation $\mathrm{CH}_{4}$ concentration than for average $\mathrm{CH}_{4}$ concentration, average $\mathrm{CO}_{2}$ concentration, and $\mathrm{CH}_{4}$-to$\mathrm{CO}_{2}$ ratio (Table 2). Residual coefficients of variation in DMI and milk yield were of similar magnitude to that of $\mathrm{CH}_{4}$-to- $\mathrm{CO}_{2}$ ratio. Repeatability was similar for eructation $\mathrm{CH}_{4}$ concentration, average $\mathrm{CH}_{4}$ concentration, average $\mathrm{CO}_{2}$ concentration, daily milk yield, milking duration, and $\mathrm{BW}$, but repeatability values for DMI, milkings per day, and $\mathrm{CH}_{4}$-to- $\mathrm{CO}_{2}$ ratio were lower than for other phenotypes (Table 2).

When cows were fed the commercial diet, rank correlations were $0.62(P<0.001)$ between ranking on eructation $\mathrm{CH}_{4}$ concentration and ranking on average $\mathrm{CH}_{4}$ concentration (Figure 3a), and $0.35(P<0.05)$ between ranking on eructation $\mathrm{CH}_{4}$ concentration and ranking on $\mathrm{CH}_{4}$-to- $\mathrm{CO}_{2}$ ratio (Figure $3 \mathrm{~b}$ ). When fed on the high-forage diets, rank correlations were $0.86(P<$ 0.001) between ranking on eructation $\mathrm{CH}_{4}$ concentration and ranking on average $\mathrm{CH}_{4}$ concentration (Figure $3 \mathrm{a})$, and $0.53(P<0.05)$ between ranking on eructation $\mathrm{CH}_{4}$ concentration and ranking on $\mathrm{CH}_{4}$-to- $\mathrm{CO}_{2}$ ratio (Figure 3b).

Rank correlation coefficients obtained by comparing ranking of cows when fed the commercial PMR and when fed the high-forage diets were high and positive for all production and emission phenotypes (Table 2). The rank correlation coefficient was higher, however, for eructation $\mathrm{CH}_{4}$ concentration than for $\mathrm{CH}_{4}$-to- $\mathrm{CO}_{2}$ ratio (Table 2; Figure 4 ).

Average heat production estimated by the equation $\left(5.6 \times \mathrm{kg} \mathrm{BW}{ }^{0.75}+22 \times \mathrm{kg}\right.$ of milk yield per day + $0.000016 \times$ days pregnant ${ }^{3} \times 0.0864$ ) of Madsen et al. (2010) was $124 \mathrm{MJ} / \mathrm{d}$ for the commercial diet, $127 \mathrm{MJ} / \mathrm{d}$ for the high-grass-silage diet, and $126 \mathrm{MJ} / \mathrm{d}$ for the high-maize-silage diet. Extrapolated estimates of daily $\mathrm{CO}_{2}$ emissions were 11,161 $\mathrm{g} / \mathrm{d}$ for the commercial diet, $11,454 \mathrm{~g} / \mathrm{d}$ for the high-grass-silage diet, and 11,308 g/d for the high-maize-silage diet. No relationship existed between observed $\mathrm{CO}_{2}$ concentrations during milking and daily $\mathrm{CO}_{2}$ emissions estimated from heat production (Figure 5). Observed average $\mathrm{CO}_{2}$ concentration was more variable $(\mathrm{CV}=18.7 \%)$ than estimated daily $\mathrm{CO}_{2}$ emission $(\mathrm{CV}=13.4 \%)$.

\section{DISCUSSION}

This study is the first to compare online methods for estimating enteric $\mathrm{CH}_{4}$ emissions from dairy cows during milking in the same individual cows. Because measurements of $\mathrm{CH}_{4}$ and $\mathrm{CO}_{2}$ were made concur- 
a)

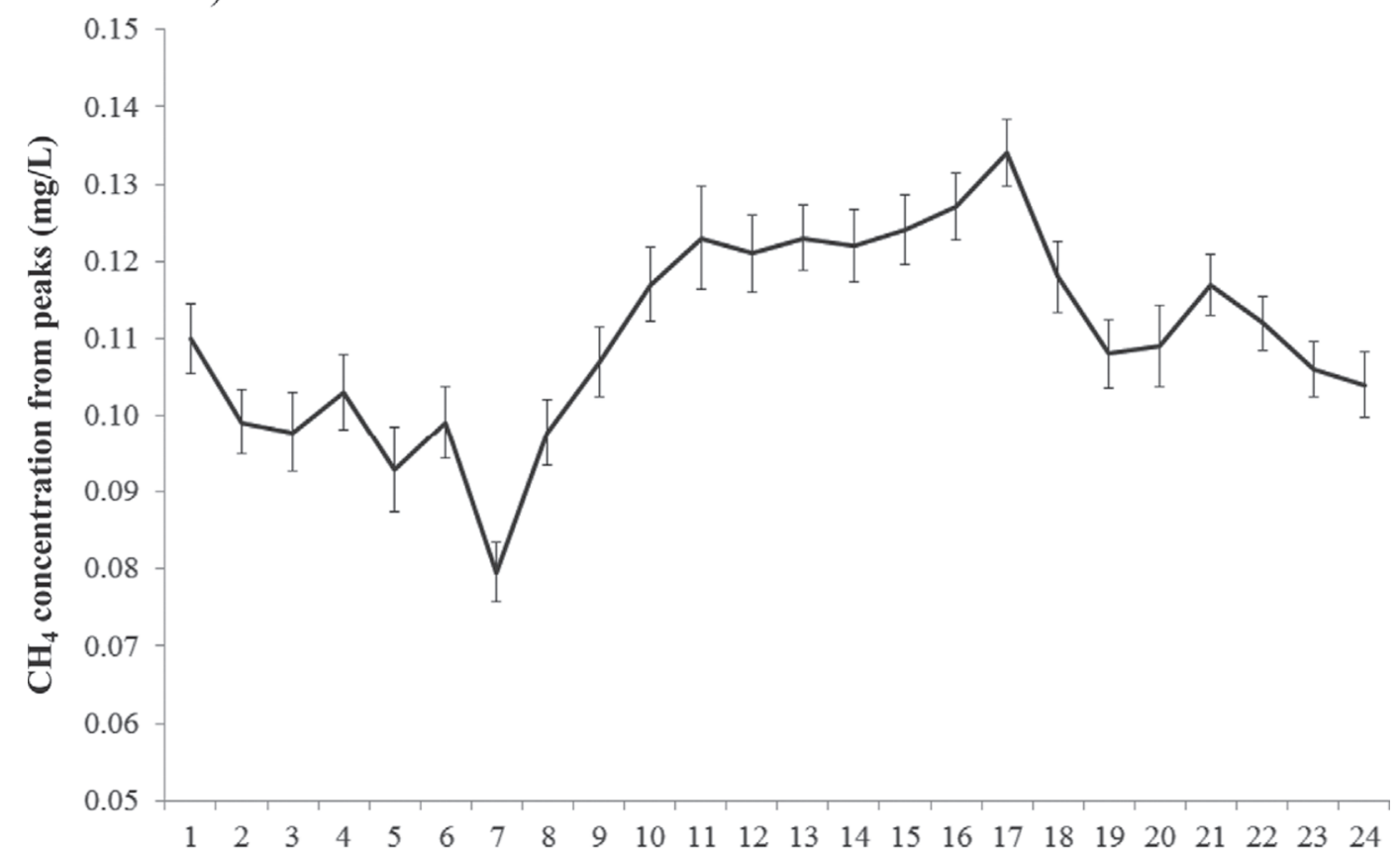

b)

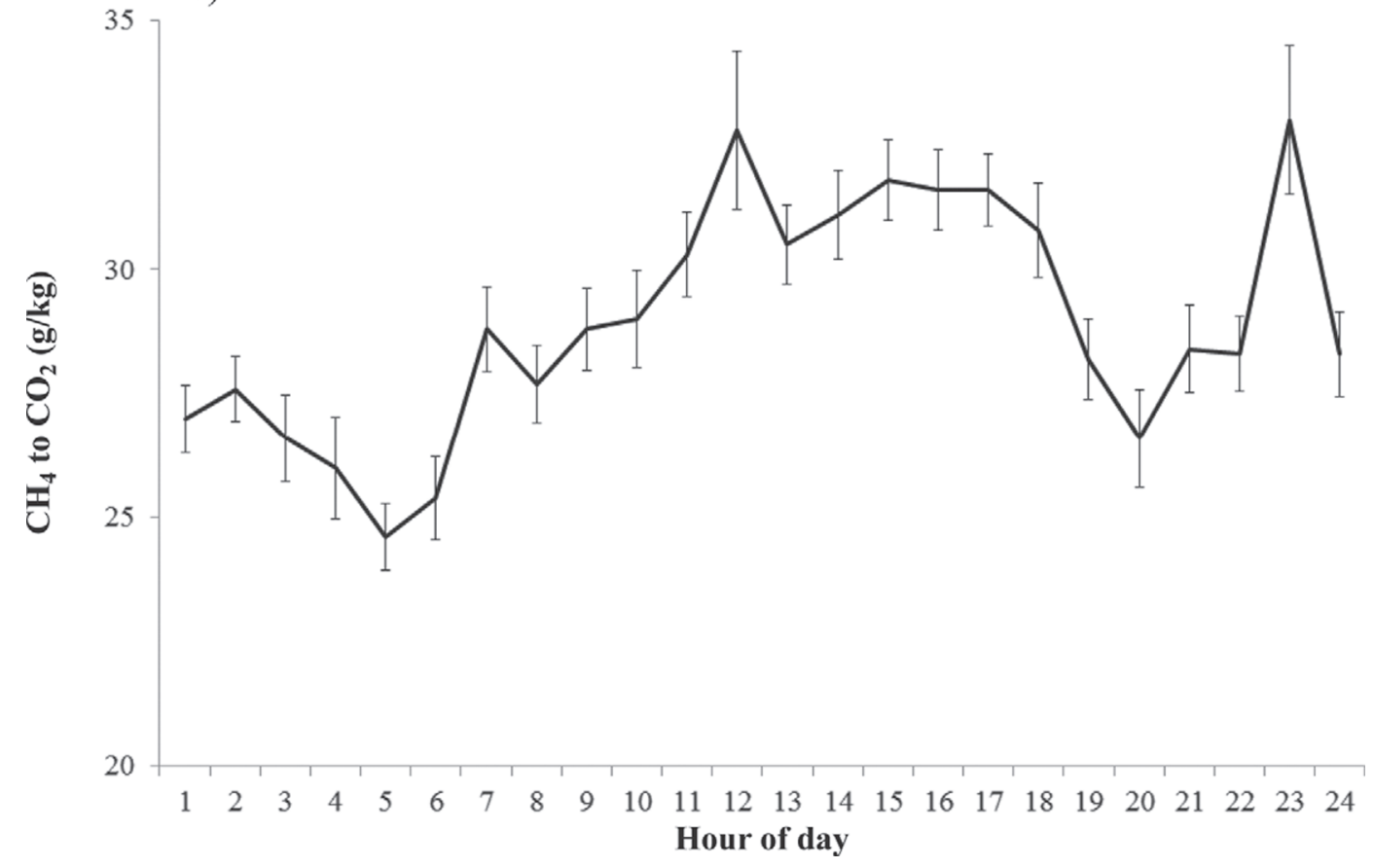

Figure 2. Average $\mathrm{CH}_{4}$ concentration (with $\mathrm{SE}$ bars) calculated from (a) eructation peaks and (b) the ratio of $\mathrm{CH}_{4}$ to $\mathrm{CO}_{2}$ concentrations for individual cows for each hour of the day from all records collected during the study period.

rently, using the same gas samples and instruments, any differences between methods can be ascribed to differences in kinetics of $\mathrm{CH}_{4}$ and $\mathrm{CO}_{2}$ release. Thus, comparisons are not confounded by differences between experimental conditions and research centers. Further- more, the design of the study permits separation of within-cow, between-cow, diet, and temporal effects on $\mathrm{CH}_{4}$ emissions to examine variation and repeatability of estimates. Quantifying variation and repeatability of phenotypes is an essential prerequisite for combining 
a)

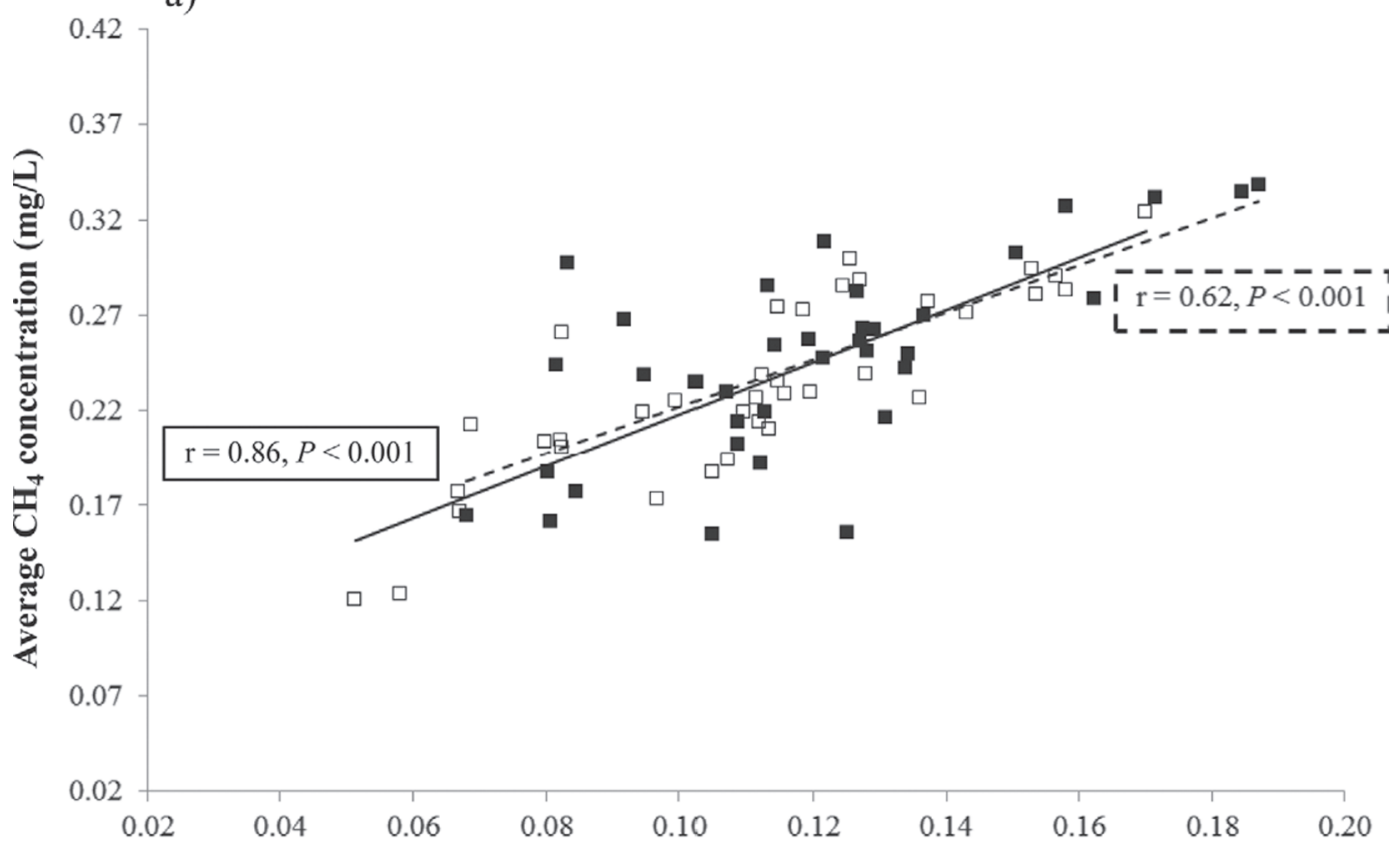

b)

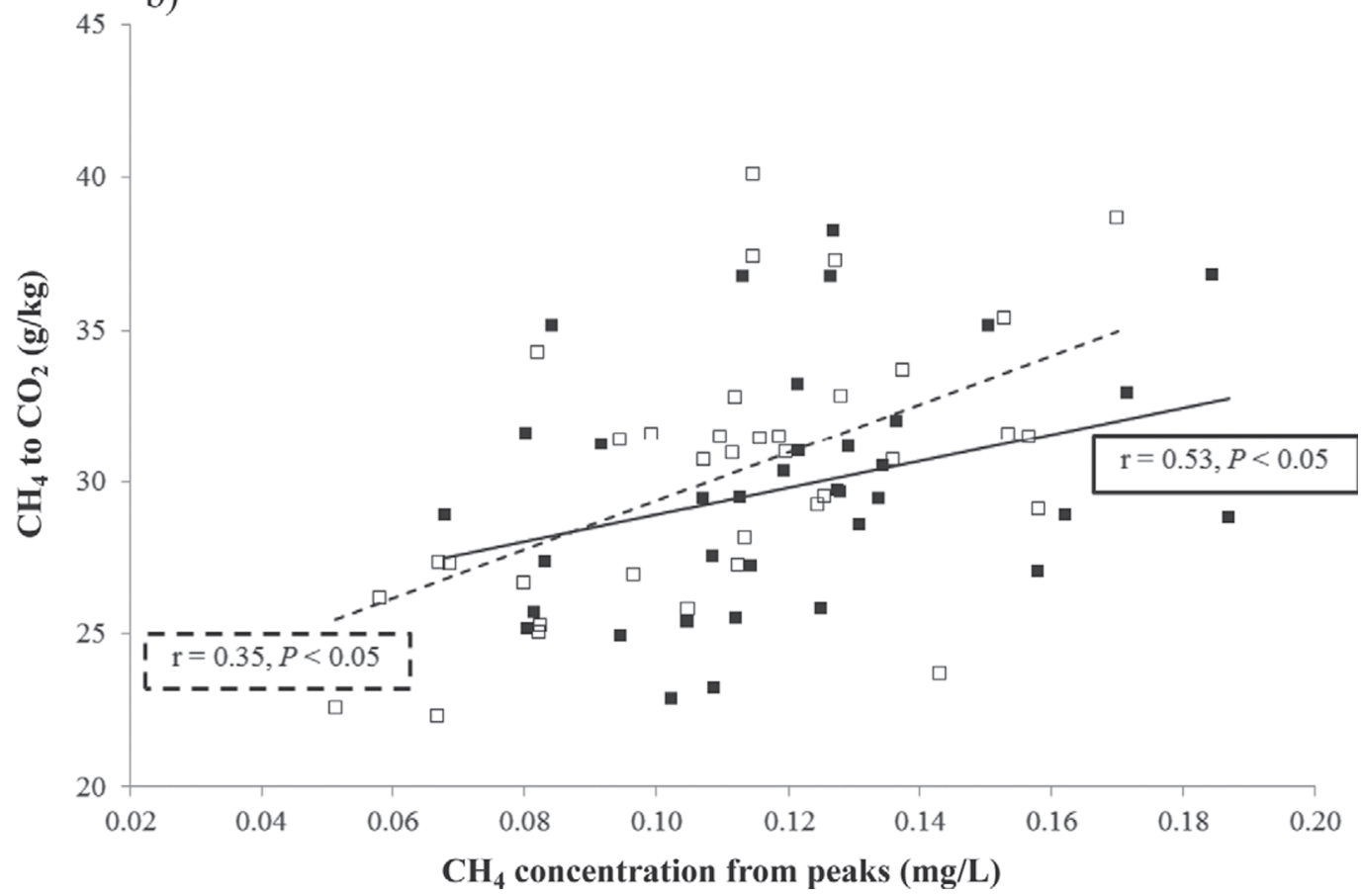

Figure 3. Relationship between $\mathrm{CH}_{4}$ concentration calculated from eructation peaks and (a) the average $\mathrm{CH}_{4}$ concentration over each milking, and (b) the ratio of $\mathrm{CH}_{4}$ to $\mathrm{CO}_{2}$ concentrations for individual cows fed a commercial partial mixed ration (PMR; $\left.\mathbf{D}\right)$ or high-forage PMR $(\square)$. The rank correlation (r) is shown with the line of best fit for the commercial PMR (dashed line) and high-forage PMR (solid line).

data sets derived by different methods in international collaborations.

Individual cow eructation $\mathrm{CH}_{4}$ was a highly repeatable phenotype, confirming our previous studies (Garn- sworthy et al., 2012a,b). Average $\mathrm{CH}_{4}$ and average $\mathrm{CO}_{2}$ concentration showed a level of repeatability similar to that of eructation $\mathrm{CH}_{4}$, but $\mathrm{CH}_{4}$-to- $\mathrm{CO}_{2}$ ratio was less repeatable. Repeatability of $\mathrm{CH}_{4}$-to- $\mathrm{CO}_{2}$ ratio (0.54) 
a)

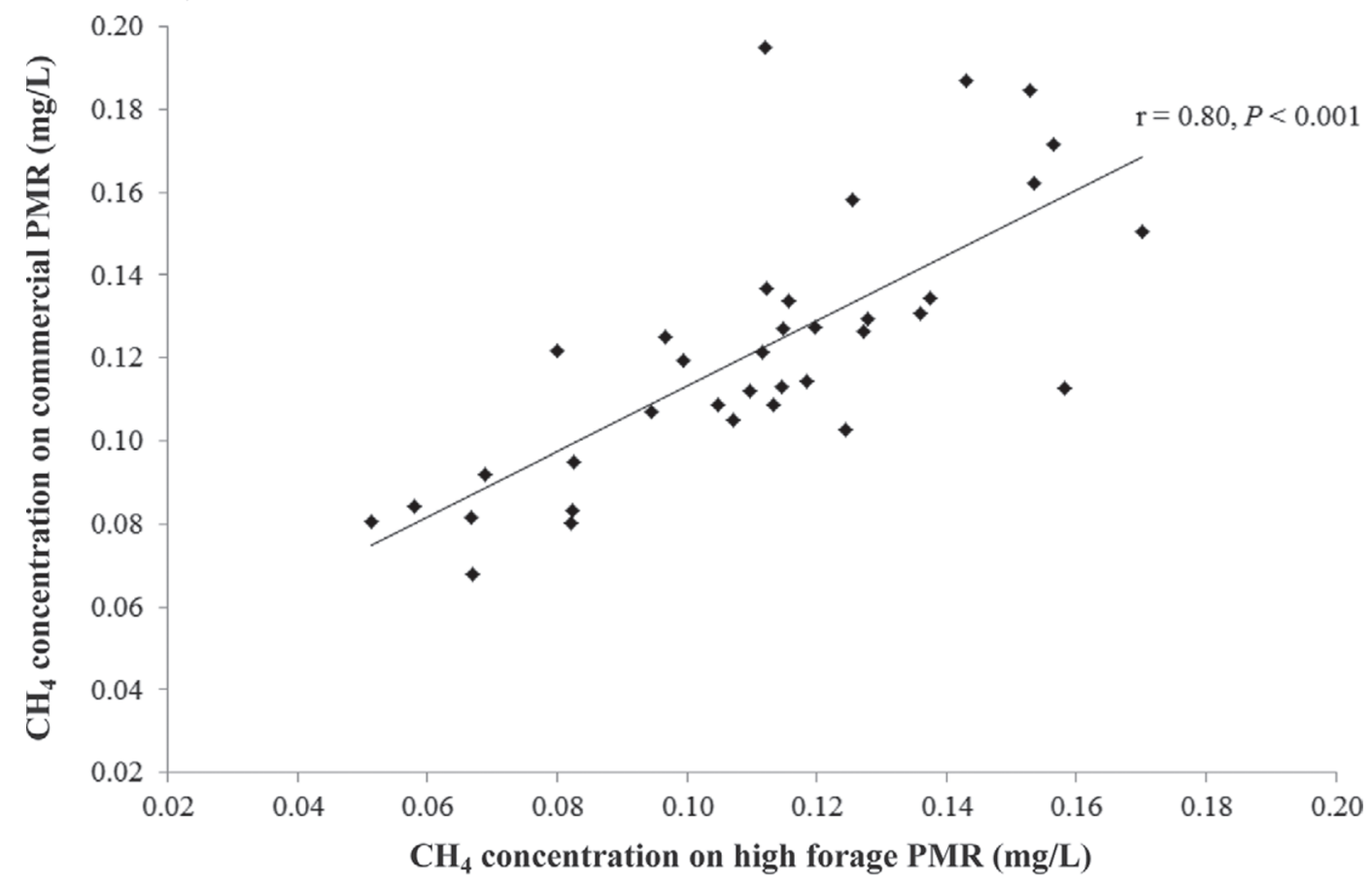

b)

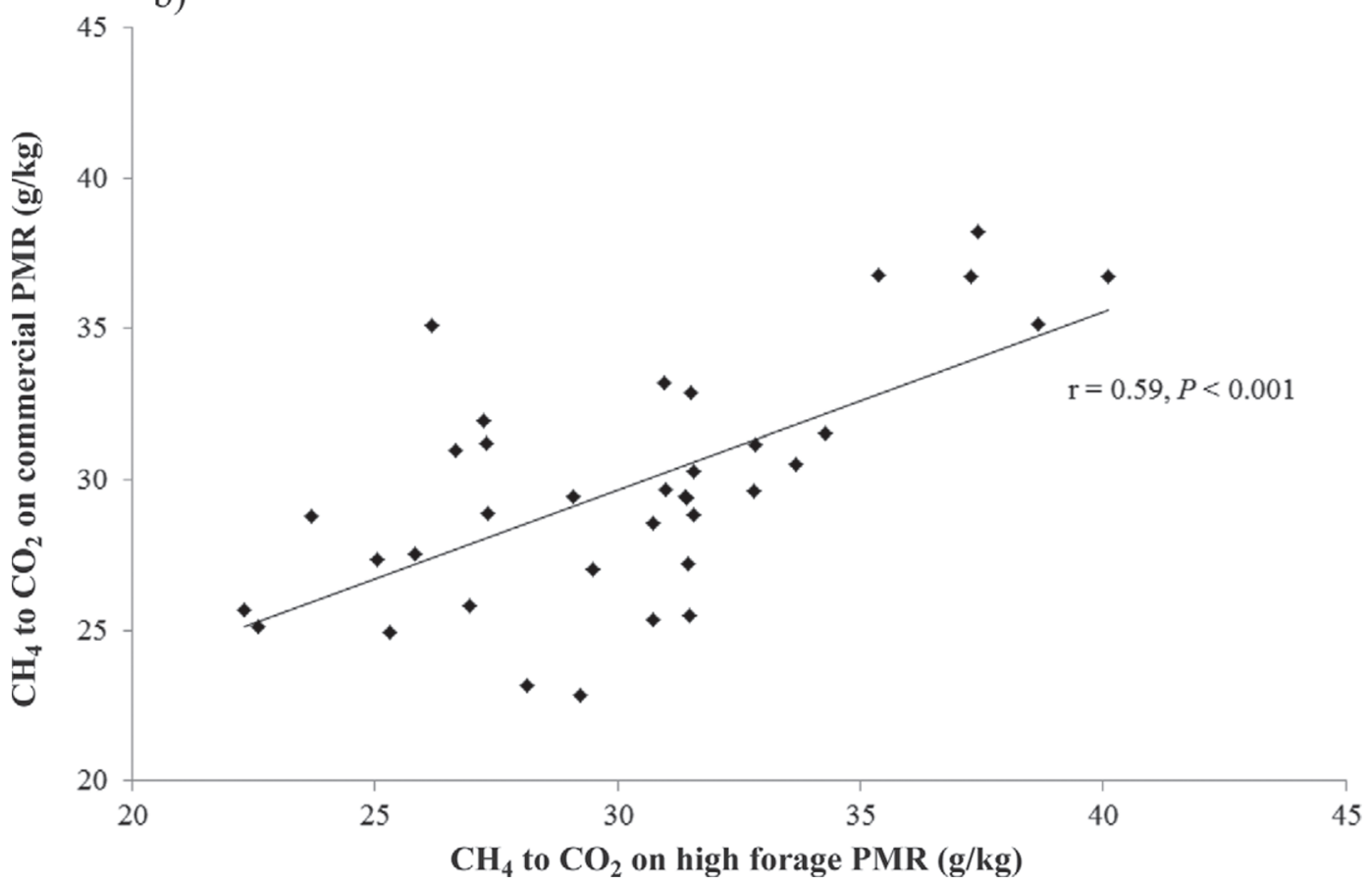

Figure 4. Relationship between $\mathrm{CH}_{4}$ concentration during milking from individual cows on a commercial partial mixed ration (PMR) and high-forage PMR calculated from (a) eructation peaks and (b) ratio of $\mathrm{CH}_{4}$ to $\mathrm{CO}_{2}$ concentrations averaged over each milking. The rank correlation ( $\mathrm{r}$ ) is shown with the line of best fit.

was higher than repeatability values of 0.37 in the study of Lassen et al. (2012), and 0.34 in experiment 1 of Huhtanen et al. (2013), although in a second experi- ment, Huhtanen et al. (2013) found a repeatability of 0.9 for $\mathrm{CH}_{4}$-to- $\mathrm{CO}_{2}$ ratio. In our previous studies, where $\mathrm{CH}_{4}$ emissions were calculated from eructation peaks, 


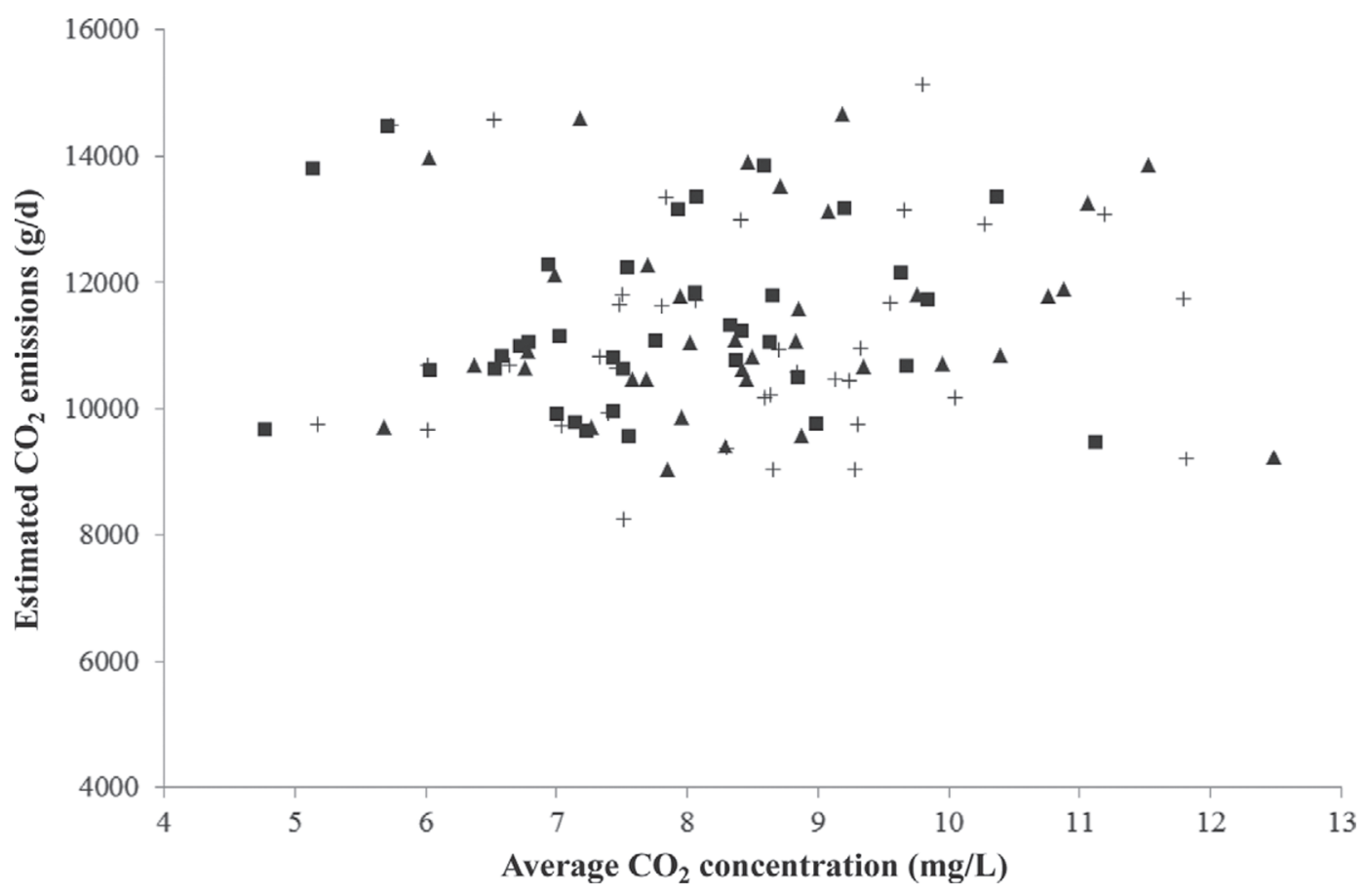

Figure 5. Relationship between average $\mathrm{CO}_{2}$ concentration over each milking and average daily $\mathrm{CO}_{2}$ emissions estimated using the method of Madsen et al. (2010) for individual cows fed commercial partial mixed ration (PMR; $\mathbf{0})$, high-grass-silage PMR (+), and high-maize-silage $\operatorname{PMR}(\mathbf{\Lambda})$.

repeatability was 0.78 between diets (Garnsworthy et al., 2012a).

Mean average $\mathrm{CH}_{4}$ concentration was approximately double the mean eructation $\mathrm{CH}_{4}$ concentration, as expected from the methods of calculation. Average $\mathrm{CH}_{4}$ concentration was calculated across each milking, subtracting the lowest concentration at the start of the milking; eructation $\mathrm{CH}_{4}$ concentration was calculated from the integral of concentrations across each eructation peak, subtracting the lowest concentration at the start of the peak. Average $\mathrm{CH}_{4}$ concentration, therefore, adjusts for changes in ambient $\mathrm{CH}_{4}$ concentration at different milkings, whereas eructation $\mathrm{CH}_{4}$ concentration adjusts not only for ambient $\mathrm{CH}_{4}$ concentration, but also for build-up of $\mathrm{CH}_{4}$ during milking, and considers only $\mathrm{CH}_{4}$ released by eructation rather than in breath.

The coefficient of variation in $\mathrm{CH}_{4}$ emissions ranged from $11 \%$ for $\mathrm{CH}_{4}$-to- $\mathrm{CO}_{2}$ ratio to $14 \%$ for eructation $\mathrm{CH}_{4}$ concentration. The greater variation in eructation $\mathrm{CH}_{4}$ concentration, average $\mathrm{CH}_{4}$ concentration, and $\mathrm{CH}_{4}$-to- $\mathrm{CO}_{2}$ ratio compared with average $\mathrm{CO}_{2}$ concentration may be explained partly by differences in the way that $\mathrm{CH}_{4}$ and $\mathrm{CO}_{2}$ are emitted by cows. Methane emissions arise from enteric fermentation, whereas $\mathrm{CO}_{2}$ emissions arise from both enteric fermentation and metabolic $\mathrm{CO}_{2}$ excreted via the lungs. For $\mathrm{CH}_{4}, 83 \%$ of daily production by sheep was released by eructation, irrespective of feeding level (Blaxter and Joyce, 1963;
Murray et al., 1976), whereas for $\mathrm{CO}_{2}$, the proportion of $\mathrm{CO}_{2}$ released by eructation varied with $\mathrm{CH}_{4}$ production and level of feeding, so that in eructed gas, $\mathrm{CO}_{2}$ concentration was $30 \%$ of $\mathrm{CH}_{4}$ concentration when $\mathrm{CH}_{4}$ production was $1 \mathrm{~L} / \mathrm{h}$ and $140 \%$ of $\mathrm{CH}_{4}$ concentration when $\mathrm{CH}_{4}$ production was $2.5 \mathrm{~L} / \mathrm{h}$ (Blaxter and Joyce, 1963). This effect would dampen variation in $\mathrm{CO}_{2}$ concentrations measured in eructed gas. When quantifying emissions from eructation peaks, it can be expected that this method would be more appropriate for identifying eructed $\mathrm{CH}_{4}$ rather than more slowly emitted $\mathrm{CO}_{2}$ emissions in breath where peaks in concentration are less defined (Figure 1). Furthermore, Blaxter and Joyce (1963) reported that during feeding, the loss of $\mathrm{CO}_{2}$ is proportionally greater than it is between meals; an observation made also in our chamber studies (Garnsworthy et al., 2012a). This is an important consideration when analyzing gas samples produced during milking in an AMS, which involves concurrent feeding.

The range in coefficient of variation among cows is within the range of 3 to $34 \%$ in coefficient of variation found in studies using respiration chambers to measure emissions in research herds (Ellis et al., 2007; Grainger et al., 2007; Yan et al., 2010), and is lower than the value of $28.8 \%$ found using eructation peaks on farm in our previous study (Garnsworthy et al., 2012a). By expressing enteric $\mathrm{CH}_{4}$ emissions as a ratio to $\mathrm{CO}_{2}$ emissions, variation among cows and repeatability of 
the phenotype were similar to variation and repeatability of DMI, which was also found by Huhtanen et al. (2013).

All $\mathrm{CH}_{4}$ emission phenotypes studied were positively $(\mathrm{r}=0.19$ to 0.24$)$ correlated with forage DMI, although only average $\mathrm{CH}_{4}$ concentration was positively $(\mathrm{r}=$ 0.22 ) associated with total DMI. Positive correlations with forage DMI are expected because $\mathrm{CH}_{4}$ arises primarily from hydrogen released during enteric fermentation of plant cell walls to produce acetate (Beauchemin et al., 2009). The lack of correlation between total DMI and eructation $\mathrm{CH}_{4}$, however, does not agree with chamber studies (e.g., Ellis et al., 2007; Grainger et al., 2007; Yan et al., 2010), in which strong positive relationships were observed. A possible explanation for this apparent discrepancy lies in the relative effects on $\mathrm{CH}_{4}$ of DMI and diet composition. Although increased DMI of most diets leads to greater $\mathrm{CH}_{4}$ production, increasing the proportion of concentrates, fat, or starch in a diet will reduce $\mathrm{CH}_{4}$ production (Beauchemin et al., 2009; Bell and Eckard, 2012). Reynolds et al. (2011) reported that increasing dietary proportions of cereal concentrates relative to forage, as indicated by ratio of starch to $\mathrm{ADF}$, reduced $\mathrm{CH}_{4}$ excretion per unit of DMI. In our previous study (Garnsworthy et al., 2012a), $\mathrm{CH}_{4}$ emission rate during milking was positively related to both total DMI and forage DMI, but negatively related to concentrate DMI. As in the current study, higher intakes of DM were associated with higher intakes of concentrates. The negative correlation between daily milk yield and eructation $\mathrm{CH}_{4}$ concentration can similarly be explained by changes in diet composition; cows with greater milk yields consumed greater proportions of high-fat concentrates fed in the AMS, which would offset increases in DMI. In another study (Bell et al., 2014), $\mathrm{CH}_{4}$ emission rate during milking for 1,964 individual cows across 21 farms was positively related to daily milk yield overall, but the relationship was positive for farms feeding grass or grass silage plus low-fat concentrates, and negative for farms feeding corn silage and high-fat concentrates.

Although total DMI and forage DMI were greater when cows were fed the high-forage PMR rather than the commercial PMR, none of the estimates of $\mathrm{CH}_{4}$ emissions differed between diets. It is possible that the lack of difference between diets is due to slightly increased concentrate consumption with the high-forage PMR; although concentrate percentage was lower than in the commercial PMR, as planned, the greater milk yield of cows resulted in a slightly greater $(+0.5 \mathrm{~kg} / \mathrm{d}$; $P=0.070)$ concentrate DMI.

A previous study on the same research herd demonstrated that measuring $\mathrm{CH}_{4}$ emissions in eructation peaks provides a method that is correlated with daily
$\mathrm{CH}_{4}$ emissions by the same cows when housed in respiration chambers (Garnsworthy et al., 2012a). As the $\mathrm{CH}_{4}$ analyzer in the current study processes $1 \mathrm{~L}$ of air/ min, the average concentration of $0.11 \mathrm{mg} / \mathrm{L}$ for cows fed a high-forage PMR (Table 2) would equate to 422 $\mathrm{g}$ of $\mathrm{CH}_{4} / \mathrm{d}$ based on the equation of Garnsworthy et al. (2012a) derived from 24-h chamber measurements [g of $\mathrm{CH}_{4} / \mathrm{d}=252+57.2 \times(0.11 \mathrm{mg} / \mathrm{min} / 0.037)$, with the analyzer sampling $3.7 \%$ of eructed gas]. This value is within the range of 278 to $456 \mathrm{~g}$ of $\mathrm{CH}_{4} / \mathrm{d}$ (mean of $369 \mathrm{~g}$ of $\mathrm{CH}_{4} / \mathrm{d}$ ) found in a study by Garnsworthy et al. (2012a) on the same herd, and similar to the average value of $430 \mathrm{~g}$ of $\mathrm{CH}_{4} / \mathrm{d}$ for dairy cows at peak milk yield reported by Cottle et al. (2011).

Using the method of Madsen et al. (2010) to estimate $\mathrm{CO}_{2}$ emissions from theoretical heat emitted by each cow in megajoules per day, the average daily $\mathrm{CH}_{4}$ emissions would be higher for cows on the high-grasssilage PMR at about $346 \mathrm{~g} / \mathrm{d}$ and lower for cows on the commercial PMR at $333 \mathrm{~g} / \mathrm{d}$. Estimates of average $\mathrm{CO}_{2}$ emitted per day derived using the method of Madsen et al. (2010) were not consistent with measured average $\mathrm{CO}_{2}$ concentration over milking (Figure 5). This is not surprising, as the equation of Madsen et al. (2010) is based on an average cow and assumes constant efficiency of energy utilization, whereas calorimeter studies show that these factors vary with animal, level of feeding, and diet composition (Yan et al., 2010). Furthermore, $\mathrm{CO}_{2}$ concentration in breath measured over a short time period varies with ventilation rate, tidal volume, eructation rate, and rumen $\mathrm{CO}_{2}$ production, and large amounts of $\mathrm{CO}_{2}$ can be lost during feeding (Blaxter and Joyce, 1963).

During early lactation when metabolic activity is high, mobilizing body energy reserves for milk production can affect $\mathrm{CO}_{2}$ emissions (Madsen et al., 2010; Lassen et al., 2012). In our previous study involving daily measurement of 215 cows over $5 \mathrm{mo}, \mathrm{CH}_{4}$ emissions increased over the first 10 wk of lactation and then declined in parallel with likely changes in DMI (Garnsworthy et al., 2012b). Further assessment of temporal variation in $\mathrm{CH}_{4}$-to- $\mathrm{CO}_{2}$ ratio is required, but the current study showed that diurnal variation exists, with the ratio being at its lowest in the morning before feeding (Figure 2), which is consistent with other studies (Kinsman et al., 1995; Lassen et al., 2012). Diurnal variation in eructation $\mathrm{CH}_{4}$ is similar to that observed in our previous study, where it was ascribed mainly to synchronized feeding behavior of the herd (Garnsworthy et al., 2012b).

Improvements in production efficiency of UK dairy systems over the last $20 \mathrm{yr}$, through genetic selection and nutrition, have reduced $\mathrm{CH}_{4}$ emissions per unit product by about $1.3 \%$ per year. Reductions will con- 
tinue, but at a slower rate per year, based on current breeding objectives (Jones et al., 2008). Greater reductions in enteric $\mathrm{CH}_{4}$ emissions are possible by selecting animals on traits associated with enteric $\mathrm{CH}_{4}$, such as feed intake or feed efficiency, without compromising production (Hegarty et al., 2007), with a theoretical potential for enteric $\mathrm{CH}_{4}$ emissions from dairy cows to be reduced by up to $2.6 \%$ per cow per year by selecting on feed efficiency (de Haas et al., 2011). A breeding objective such as selecting cows for low $\mathrm{CH}_{4}$ emissions per unit DMI or kilograms of milk may be a more costeffective phenotype than feed intake and would include selection on energy utilization efficiency, which has not been possible in the past. To generate sufficient data for analyzing $\mathrm{CH}_{4}$ phenotypes requires combining international data sets, derived using different methods. The current study provides initial evidence that such phenotypes are correlated, but that refinement is required before equivalence can be established.

\section{CONCLUSIONS}

This study showed that quantifying enteric $\mathrm{CH}_{4}$ emissions using eructation peaks in concentration or as a ratio to $\mathrm{CO}_{2}$ emissions averaged over a milking can provide a highly repeatable phenotype for ranking cows on $\mathrm{CH}_{4}$ output. No significant difference existed between $\mathrm{CH}_{4}$ and $\mathrm{CO}_{2}$ emissions from the same cows when fed diets containing different percentages and types of forage. Considerable variation in enteric $\mathrm{CH}_{4}$ emissions exists among cows. All $\mathrm{CH}_{4}$ emission phenotypes studied were positively correlated with forage DMI. Importantly, significant correlations existed in ranking cows on emissions of $\mathrm{CH}_{4}$ calculated from eructation peaks or as $\mathrm{CH}_{4}$-to- $\mathrm{CO}_{2}$ ratio, although calculation of $\mathrm{CH}_{4}$ emissions from eructation peaks produced a more repeatable phenotype.

\section{ACKNOWLEDGMENTS}

This work was funded by the Department for Environment, Food and Rural Affairs (Defra, London, UK), the Scottish Government, Department of Agriculture and Rural Development (DARD, Belfast, UK), and the Welsh Government as part of the UK Agricultural Greenhouse Gas (GHG) Research Platform project (http://www.ghgplatform.org.uk). The authors thank the farm staff for their assistance with the study.

\section{REFERENCES}

Beauchemin, K. A., T. A. McAllister, and S. M. McGinn. 2009. Dietary mitigation of enteric methane from cattle. CAB Rev. Perspec. Agric. Vet. Sci. Nutr. Nat. Resour. 4:1-18.
Bell, M. J., and R. J. Eckard. 2012. Reducing enteric methane losses from ruminant livestock-Its measurement, prediction and the influence of diet. Pages 135-150 in Livestock Production. K. Javed, ed. InTech Publishing, Rijeka, Croatia.

Bell, M. J., S. L. Potterton, J. Craigon, N. Saunders, R. Wilcox, M. Hunter, J. R. Goodman, and P. C. Garnsworthy. 2014. Variation in enteric methane emissions among cows on commercial dairy farms. Animal 8:1540-1546. http://dx.doi.org/10.1017/ S1751731114001530.

Blaxter, K. L., and J. P. Joyce. 1963. The accuracy and ease with which measurements of respiratory metabolism can be made with tracheostomized sheep. Br. J. Nutr. 17:523-537.

Cottle, D. J., J. V. Nolan, and S. G. Wiedemann. 2011. Ruminant enteric methane mitigation: A review. Anim. Prod. Sci. 51:491-514.

de Haas, Y., J. J. Windig, M. P. L. Calus, J. Dijkstra, M. de Haan, A. Bannink, and R. F. Veerkamp. 2011. Genetic parameters for predicted methane production and the potential for reducing enteric emissions through genomic selection. J. Dairy Sci. 94:6122-6134.

Ellis, J. L., E. Kebreab, N. E. Odongo, B. W. McBride, E. K. Okine, and J. France. 2007. Prediction of methane production from dairy and beef cattle. J. Dairy Sci. 90:3456-3466.

Garnsworthy, P. C., J. Craigon, J. H. Hernandez-Medrano, and N. Saunders. 2012a. On-farm methane measurements during milking correlate with total methane production by individual dairy cows. J. Dairy Sci. 95:3166-3180.

Garnsworthy, P. C., J. Craigon, J. H. Hernandez-Medrano, and N. Saunders. 2012b. Variation among individual dairy cows in methane measurements made on farm during milking. J. Dairy Sci. 95:3181-3189.

Grainger, C., T. Clarke, S. M. McGinn, M. J. Auldist, K. A. Beauchemin, M. C. Hannah, G. C. Waghorn, H. Clark, and R. J. Eckard. 2007. Methane emissions from dairy cows measured using the sulfur hexafluoride $\left(\mathrm{SF}_{6}\right)$ tracer and chamber techniques. J. Dairy Sci. 90:2755-2766.

Hegarty, R. S., J. P. Goopy, R. M. Herd, and B. McCorkell. 2007. Cattle selected for lower residual feed intake have reduced daily methane production. J. Anim. Sci. 85:1479-1486.

Huhtanen, P., S. J. Krizsan, M. Hetta, H. Gidlund, and E. H. Cabezas Garcia. 2013. Repeatability and between cow variability of enteric methane and total carbon dioxide emissions. Adv. Anim. Biosci. 4:588. (Abstr.)

Jones, H. E., C. C. Warkup, A. Williams, and E. Audsley. 2008. The effect of genetic improvement on emission from livestock systems. Page 28 in Proc. Eur. Assoc. Anim. Prod., Vilnius, Lithuania. Wageningen Academic Publishers, Wageningen, the Netherlands.

Kinsman, R., F. D. Sauer, H. A. Jackson, and M. S. Wolynetz. 1995. Methane and carbon dioxide emissions from dairy cows in full lactation monitored over a six-month period. J. Dairy Sci. 78:2760 2766 .

Lassen, J., P. Løvendahl, and J. Madsen. 2012. Accuracy of noninvasive breath methane measurements using Fourier transform infrared methods on individual cows. J. Dairy Sci. 95:890-898.

Lawes Agricultural Trust. 2012. GenStat 15, Version 15.1 Reference Manual. Clarendon Press, London, UK.

Madsen, J., B. S. Bjerg, T. Hvelplund, M. R. Weisbjerg, and P. Lund. 2010. Methane and carbon dioxide ratio in excreted air for quantification of the methane production from ruminants. Livest. Sci. 129:223-227.

Murray, R. M., A. M. Bryant, and R. A. Leng. 1976. Rates of production of methane in the rumen and large intestine of sheep. Br. J. Nutr. 36:1-14.

Reynolds, C. K., L. A. Crompton, and J. A. N. Mills. 2011. Improving the efficiency of energy utilisation in cattle. Anim. Prod. Sci. 51:6-12.

Yan, T., C. S. Mayne, F. G. Gordon, M. G. Porter, R. E. Agnew, D. C. Patterson, C. P. Ferris, and D. J. Kilpatrick. 2010. Mitigation of enteric methane emissions through improving efficiency of energy utilization and productivity in lactating dairy cows. J. Dairy Sci. 93:2630-2638. 